\title{
Ensino de Sociologia: Particularidades E Desafios Contemporâneos
}

\author{
Nise Jinkings ${ }^{l}$
}

\begin{abstract}
Resumo
Este trabalho busca realizar um desenho analítico das particularidades e das condições do ensino de Sociologia nas escolas brasileiras de nível médio. Trata do lugar da Sociologia no sistema educacional do país, de suas potencialidades educativas e dos dilemas enfrentados desde sua institucionalização como disciplina científica, na década de 1930. A análise trás elementos para se pensar os desafios colocados às ciências sociais e aos educadores no contexto da realidade social contemporânea e de suas novas determinações. Apoiado em atividades de ensino, pesquisa e extensão, 0 trabalho desenvolve reflexão sobre experiências formativas e apresenta um diagnóstico inicial das condições concretas em face das quais se realiza o ensino da disciplina nas escolas de Santa Catarina. Palavras-chave: Sociologia. Ensino de Sociologia. Ensino Médio. Educação escolar.
\end{abstract}

\begin{abstract}
The aim of this study is to perform an analytical design of the particularities and conditions of the teaching of sociology in Brazilian high schools. It deals with the placement of sociology within the educational system of the country, of its educational potentials and dilemmas since its institutionalization as a scientific subject in the 1930's. The analysis sets forth elements for a reflection on the challenges of both the social sciences and educators within the context of contemporary social reality and its determinations. Supported by teaching, research and extension activities alike, this study engenders reflections on formative experiences and presents an initial diagnosis of the concrete conditions in which this discipline is taught within the schools of Santa Catarina. Key words: Sociology. Teaching of sociology. HIGH school. School education.
\end{abstract}

$1 \begin{aligned} & \text { Sociologia confronta-se permanentemente com desafios teóricos e metodológicos } \\ & \text { inerentes ao seu objeto de estudo: a realidade social em movimento. Este objeto } \\ & \text { vivo, contraditório, em contínua transformação, torna-se mais complexo à medida }\end{aligned}$ que se desenvolvem novas configurações e possibilidades da vida em sociedade. Neste

${ }^{1}$ Professora do Departamento de Metodologia de Ensino e do Programa de Pós-Graduação em Educação do Centro de Ciências da Educação, Universidade Federal de Santa Catarina. 
sentido, pode-se dizer que a Sociologia é uma ciência que tem a singularidade de se questionar o tempo todo, repensando princípios explicativos e teorias, produzindo novas interpretações da vida social, recriando polêmicas e embates metodológicos.

Nos dias de hoje, diante de mudanças velozes que transformam o capitalismo mundial e atingem todas as esferas da vida em sociedade, repercutindo nas formas de pensar e agir, nos sistemas de poder, nas condições de vida e trabalho, nas maneiras de organização espacial e do tempo, a Sociologia encontra-se desafiada a repensar e a recriar conceitos, formulações e modos de interpretação da sociabilidade contemporânea. 0 processo em curso de mundialização do capitalismo engendra uma realidade social que envolve configurações e dinâmica próprias, com importantes implicações metodológicas, empíricas e epistemológicas para as ciências sociais.

São muitos os cientistas sociais que buscam apreender a natureza e o significado das mudanças em curso. Múltiplas interpretações dos movimentos que constituem a sociedade capitalista contemporânea fazem florescer distintas perspectivas e teorias, que se empenham na sua explicação e compreensão. Conceitos e expressões como "globalização", "neoliberalismo", "contra-revolução liberal-conservadora", "mundialização financeira", "aldeia global", "modernidade-mundo", "mundo virtual", "reestruturação produtiva", "qualidade total", aparecem nos estudos e debates sobre as novas configurações do capitalismo e os processos compreendidos nas formas de sociabilidade engendradas. Aspectos como a intensa mobilidade e concentração do capital, os processos de liberalização econômica e de desregulamentação financeira, a mudança veloz das condições técnicas e sociais da produção, a nova divisão internacional do trabalho e a formação de blocos geoeconômicos e geopolíticos, o desenvolvimento vertiginoso da comunicação eletrônica e a constituição de uma cultura de massa em âmbito mundial são retratados nas análises e formulações sobre os sentidos e a dinâmica destes movimentos.

Vista em sua historicidade, a nova realidade social ilumina processos que se vinham desenvolvendo mais intensamente desde o último quartel do século passado, quando o mundo "resvalou para a instabilidade e a crise", nas palavras de Eric Hobsbawm (1997). Com efeito, desde meados da década de 1970 uma longa depressão econômica tem caracterizado a conjuntura mundial, fazendo ressurgir contradições inerentes ao capitalismo, em grande medida submersas nos chamados "anos dourados" posteriores à Segunda Guerra. Diversos pensadores interpretam esse novo momento da história social, econômica e política mundial como expressão de uma crise capitalista profunda e de um movimento de reorganização do capital, na tentativa de superação deste quadro crítico (MÉSZÁROS, 1995). ${ }^{2}$

${ }^{2}$ Ver (edição brasileira: Para Além do Capital, 2002); Chesnais (1996); Teixeira (1996); Brenner (1999); Antunes (2000). 
Ao refletir sobre os novos desafios teóricos e metodológicos que os atuais movimentos da sociedade capitalista mundial impõem à sociologia, Octavio Ianni (2001) assinala que o novo ciclo de globalização capitalista sob o predomínio do neoliberalismo, que torna a sociedade civil mundial o principal palco da história e das tensões das forças sociais, engendra uma realidade social que exige novas reflexões, conceitos, interpretações e se constitui no novo emblema da sociologia, abrindo-lhe potencialidades e horizontes.

0 autor relembra os principais emblemas que inspiram e polarizam a análise sociológica nos dias de hoje: sociedade nacional, sob o qual nasce a sociologia no século XIX, fruto das revoluções industriais, político-sociais e culturais que abalaram o mundo moderno ocidental; o indivíduo, que adquire proeminência na passagem do século XIX para o século XX, quando a Sociologia volta-se para o ator social, a identidade e 0 cidadão; a sociedade global, como totalidade complexa e realidade social nova que desafia o ensino e a pesquisa desde o final do século passado, envolvendo configurações e dinâmica próprios, com importantes implicações metodológicas, empíricas e epistemológicas para as ciências sociais (IANNI, 1997).

Disciplina científica da modernidade, a Sociologia surge e se desenvolve no contexto das fermentações intelectuais e crises sociais produzidas nas modernas sociedades de classes. Florestan Fernandes (2000), a tratar da herança intelectual da Sociologia, ressalta sua vinculação com as condições histórico-sociais de existência, assinalando que foram exigências e necessidades das situações concretas de existência social que levaram à constituição da Sociologia como explicação científica do mundo social. ${ }^{3}$

Mas a análise sociológica, ao mesmo tempo em que contribui para uma compreensão sistemática, totalizante e rigorosa da realidade social, incorpora-se aos movimentos desta realidade e participa de sua constituição. Como assinala Ianni (1997, p. 25),

a Sociologia pode ser vista como uma forma de autoconsciência da realidade social. Essa realidade pode ser local, nacional, regional ou mundial, micro ou macro, mas cabe sempre a possibilidade de que ela possa pensar-se criticamente, com base nos recursos metodológicos e epistemológicos que constituem a Sociologia como disciplina científica. [...] Ocorre que a Sociologia pode tanto decantar a tessitura e a dinâmica da realidade social como participar da constituição dessa tessitura e dinâmica. Na medida em que o conhecimento sociológico se produz, logo entra na trama das relações sociais, no jogo das forças que organizam e movem, tensionam e rompem a tessitura e a dinâmica da realidade social.

\footnotetext{
${ }^{3}$ Ver também Bottomore e Nisbet (Org.) 1980.
} 
Forma de autoconsciência e de indagação científica da realidade social, a Sociologia transforma-se continuamente à medida que se modifica e se complexifica seu objeto, repensando teorias, conceitos e recursos metodológicos, sem perder a dimensão histórica dos fenômenos sociais. Tendo como objeto a vida em sociedade nos seus movimentos e em transformação constante, o pensamento sociológico guarda relação complexa com as condições de existência social e com os desafios e necessidades práticos dos seres humanos, em diferentes momentos de sua história. Ao mesmo tempo, pelas suas conceituações e reflexões, desvenda contradições, singularidades e universalidades constitutivas da realidade social, que implicam possibilidades de críticae de transformação desta mesma realidade.

Essas são algumas particularidades da Sociologia, que transparecem nas suas controvérsias teóricas e metodológicas e envolvem suas atividades de pesquisa e de ensino. Na atualidade, em face de um projeto de sociabilidade que ata a vida social e política aos movimentos do mercado e busca se afirmar como irreversível, os desafios com que se depara a Sociologia são os de iluminar a natureza e o significado da dinâmica, das contradições e das relações sociais que emergem nesta nova realidade. Neste sentido, a Sociologia pode contribuir para pensar, na sua historicidade, o mundo social resultante do modo como o capital se reproduz em nossos dias.

\section{SOCIOLOGIA E EDUCAÇÃo No BRASIL}

"Somente quem vê algo sociologicamente quer algo socialmente". Com esta frase, Florestan Fernandes (1978, p. 22-28) sintetiza o que ele considerava uma das funções do ensino de Ciências Sociais nas escolas e universidades, na sociedade brasileira de meados do século XX: a capacitação dos jovens estudantes para uma participação consciente na vida social e política. Isto na medida que as ciências sociais permitem desobstruir o horizonte intelectual e libertá-lo das concepções tradicionais e religiosas do mundo, assim como dos "efeitos sedativos da propaganda", que manipula a opinião pública para determinados fins e se "infiltra em nossa mente de fora para dentro". Nesta perspectiva, as ciências sociais potencializam uma compreensão ampla do mundo social e a formação do "novo tipo de homem" exigido pela sociedade da época.

Tal expectativa com relação às funções educativas das ciências sociais é coerente com o percurso seguido pela Sociologia ao ingressar na comunidade científica e no sistema educacional brasileiro. Sabe-se que no Brasil as condições propícias ao desenvolvimento das ciências sociais verificam-se com a desagregação do regime escravocrata e senhorial e a transição para um regime de classes, quando concepções secularizadas da existência social, explicações racionais da atividade política, econômica 
e administrativa e a exploração sistemática de recursos técnicos e científicos questionam valores vinculados à ordem vigente. Neste sentido, o significado da desagregação do regime senhorial para o surgimento e a formação da Sociologia no país é semelhante ao da revolução burguesa, para o seu desenvolvimento na Europa.

Foi visando contribuir para o desmonte das idéias que davam sustentação à ordem patrimonialista e escravocrata, que a Sociologia chegou aos cursos voltados à formação de educadores do ensino básico, no final do século XIX, sob a influência das idéias positivistas de Auguste Comte. Naquele contexto, os estudos sociológicos associaram a Sociologia à moral e buscaram formar uma nova mentalidade, mais voltada para as "ciências positivas", conforme Fernando de Azevedo (1964).

A efervescência social, política, intelectual e cultural do início do século XX, expressa no Brasil em acontecimentos e movimentos como o tenentismo, as lutas operárias, a fundação do Partido Comunista Brasileiro, a Semana de Arte Moderna, as chamadas Revolução de 1930 e Revolução Constitucionalista de 1932, favorecia a reflexão sobre a vida social e o sistema capitalista que se estruturava no país. Florestan Fernandes (1980) observa que à constituição dessa nova ordem social, associa-se a formação de um novo ambiente cultural e intelectual voltado para 0 saber racional e 0 interesse pela análise histórico-sociológica da sociedade brasileira, que se complexifica com a expansão urbana e a industrialização.

Naquelas primeiras décadas do século XX a Sociologia desenvolvia-se como "ponto de vista", no dizer de Antonio Candido (1976), influenciando a literatura brasileira. Segundo ele, a análise sociológica aparecia em um "gênero misto de ensaio, construído na confluência da história com a economia, a filosofia ou a arte", "forma bem brasileira de investigação e descoberta do Brasil". 0 autor cita obras como Os Sertões, de Euclides da Cunha; História da Literatura Brasileira, de Sílvio Romero; Populações Meridionais do Brasil, de Oliveira Vianna, As Raízes do Brasil, de Sérgio Buarque de Hollanda e a obra de Gilberto Freire, como exemplos destas abordagens sociológicas da realidade brasileira.

No período colonial, vale lembrar, os papéis intelectuais e vinculados à educação foram praticamente monopolizados pelo clero, que operava como força de conservantismo cultural. Fernandes (1980) analisa as mudanças que se operam na esfera da educação e as novas funções a ela atribuídas para responder aos desafios e necessidades da emergente sociedade urbana e democrática. Segundo ele, a integração da Sociologia no sistema sócio-cultural brasileiro se dá no contexto de transformações paralelas na estrutura social e na organização da cultura, que alteram o antigo sistema institucional e ao mesmo tempo criam novas instituições. Em especial nas regiões em que se desenvolveram de 
modo acelerado os processos de urbanização, de industrialização e de diferenciação social, as mudanças na divisão do trabalho e no sistema escolar estimularam a constituição da Sociologia como especialidade e a institucionalização de suas atividades de ensino e pesquisa. Simultaneamente a esta institucionalização, estruturam-se papeis sociais que passam a dar suporte à sociologia como especialidade científica - professor, assistente, pesquisador, técnico, auxiliar de ensino - e se organizam em novas bases as tarefas da produção sociológica e o trabalho profissional dos sociólogos, que adquire o caráter de carreira regulada academicamente.

Diversos estudiosos dos condicionantes do desenvolvimento das ciências sociais no Brasil referem-se à década de 1930 como o momento no qual se inicia o seu processo de institucionalização. A Sociologia, ao lado da Antropologia e da Ciência Política, passa a ser reconhecida como conhecimento especializado, ocupando, enfim, um lugar institucional (MEUCCI, 2000). ${ }^{4}$

Com efeito, nos anos 1930 um conjunto amplo de transformações sociais implica um rompimento mais efetivo com as condições de sociabilidade estabelecidas, radicalizando um movimento de mudança que se desenvolvia desde os primeiros anos do século e implicando na percepção, pelas elites intelectualizadas, da necessidade das análises de cunho sociológico. No período, um conjunto de iniciativas governamentais consolida o lugar da Sociologia na estrutura do sistema nacional de ensino, tanto nas escolas de nível médio, como na formação em nível superior. De acordo com Costa Pinto e Carneiro (1955), os investimentos na institucionalização das ciências sociais resultaram de um entendimento das elites dirigentes quanto à função destas ciências, particularmente da Sociologia, como ferramentas de progresso social, que orientariam a ação e contribuiriam para a integração nacional.

Um forte impulso às análises sociológicas no campo da educação e à introdução das ciências sociais nos currículos das escolas de nível médio é dado pelo movimento pela renovação pedagógica designado de "Escola Nova", que inspira e orienta reformas educacionais em várias regiões do Brasil. Cientistas sociais vinculados a Escola Nova como Fernando de Azevedo, Anísio Teixeira, Delgado de Carvalho, dentre outros, buscaram na Sociologia os fundamentos científicos para a elaboração de reformas e programas de política educacional. Em São Paulo, o movimento destes educadores protagonizou a Reforma Sampaio Dória, de 1920, que modernizou métodos pedagógicos, ampliou o número de escolas e projetou a Faculdade de Educação; a Reforma Lourenço Filho, de 1931, que introduziu cursos de aperfeiçoamento para professores primários; a Reforma Fernando de Azevedo, de 1933, que criou o Instituto de Educação, incorporado posteriormente à Universidade de São Paulo (LIMONGI, 1989, p. 128-9) .

${ }^{4}$ Ver também Chacon (1977). 
Destaca-se no período a Reforma Rocha Vaz, de 1925 e de âmbito nacional, pela qual a Sociologia incorpora-se ao sistema de ensino como disciplina obrigatória da 6 . série do curso ginasial, no quadro da crise social e política que assinalou o fim da Primeira República. Em 1931, a Reforma Francisco Campos reforçaria a inserção da Sociologia no sistema, determinando sua incorporação nos currículos dos cursos complementares - com duração de dois anos, dirigidos aos alunos que, após o curso secundário, preparavam-se para ingressar nas faculdades e universidades - e exigindo seu conteúdo nos exames de seleção para os cursos de nível superior.

Na mesma década, entre 1933 e 1935, a criação de diversas instituições de ensino superior - Escola Livre de Sociologia e Política de São Paulo, Universidade de São Paulo e Universidade do Distrito Federal, no Rio de Janeiro - abre novo espaço para a investigação e o ensino de Sociologia. A introdução da disciplina nos cursos destas universidades trazia para os primeiros sistematizadores do conhecimento sociológico no Brasil, formados nos cursos de direito, o desafio de convertê-la aos padrões acadêmicos, definindo sua especificidade e seus procedimentos científicos, articulando-a a um campo de pesquisas e constituindo a identidade do sociólogo, como novo profissional especializado (MEUCCI, 2000).

As transformações que atingiam o Brasil, de modo desigual e em ritmos diferenciados entre suas diversas regiões, implicavam mudanças na composição e na ideologia das camadas sociais dominantes. Vinculadas aos ideais republicanos e liberais, essas camadas conceberam um projeto político-educacional, o qual convertia a Universidade em instrumento de formação das elites dirigentes que promoveriam a "modernização" da sociedade brasileira.

0 incentivo ao ensino de ciências sociais no país, naquele contexto, respondia a interesses e preocupações práticas da intelectualidade liberal, com vistas à retomada da hegemonia política perdida após as revoluções de 1930 e 1932. Ao comentar a criação de instituições de ensino superior em São Paulo, como a Faculdade de Filosofia, Ciências e Letras da USP, em 1934, e a Escola Livre de Sociologia e Política, em 1933, Fernandes (1980a) refere-se aos seguintes propósitos dos seus fundadores: formar os futuros membros da elite dirigente e "intervir na preparação das novas gerações, de modo a proporcionar-lhes técnicas racionais capazes de permitir a solução dos problemas sociais brasileiros sem pressão social nem conflitos". Desse modo, as ciências sociais ficavam reduzidas a uma espécie de "engenharia social", cuja finalidade seria a contenção dos conflitos sociais.

Disciplina obrigatória no ensino de nível médio durante toda a década de 30, a Sociologia foi afastada dos currículos das escolas e mantida apenas nos cursos de magistério 
das antigas escolas normais, pela reforma educacional implementada durante 0 Estado Novo, sob a orientação do então ministro Gustavo Capanema (MACHADO, 1987). A possibilidade de reinserção da disciplina nos cursos de nível médio torna-se objeto de debates no meio intelectual com o fim do regime ditatorial, durante o período assinalado pela tentativa de desenvolvimento de um processo democrático no país, em certa medida inédito, face o caráter oligárquico da organização republicana no Brasil.

Um exemplo desses debates nos ambientes universitários é o que se desenvolveu no Symposium sobre o Ensino da Sociologia e da Etnologia, com a participação de professores e estudantes dos cursos de Ciências Sociais da Faculdade de Filosofia, Ciências e Letras da USP e da Escola Livre de Sociologia e Política, em São Paulo. Nele foram apresentadas análises que apontavam para a necessidade e a finalidade da integração efetiva da Sociologia no sistema educacional brasileiro e tratavam das potencialidades educativas do professor da disciplina no país. ${ }^{5}$

Durante o I Congresso Brasileiro de Sociologia, em 1954, ao apresentar a comunicação "0 ensino de Sociologia na escola secundária brasileira", ${ }^{6}$ Florestan Fernandes analisa as possibilidades de introdução da Sociologia nas escolas de ensino médio, a partir de uma reflexão que relaciona o sistema educacional brasileiro às condições sócio-culturais nas quais ele se insere. De acordo com sua reflexão, o ensino médio de então ocupava uma função auxiliar e dependente no sistema, na medida que se voltava, privilegiadamente, para a preparação dos estudantes com vistas ao seu ingresso nas escolas de nível superior. 0 autor define-o como um ensino de caráter enciclopédico, meramente aquisitivo e preso à antiga e conservadora mentalidade educacional, distante das necessidades intelectuais da época e incapaz de se converter em instrumento consciente de transformação social. Um sistema contraditório, dominado por práticas e interesses conservadores, cerceadores das tentativas de renovação pedagógica e de enfrentamento das exigências educativas impostas pelas novas condições de existência social. São contradições que se explicam, em grande medida, pelo modo como se organiza a sociedade brasileira, marcada por desigualdades, heterogeneidades e contrastes. Instituições sociais como a família e a igreja seguiam mantendo influência significativa nas atividades educativas, particularmente nas muitas regiões do país não atingidas pelos efeitos do processo de secularização da vida social e cultural (FERNANDES, 1980b).

0 autor assinala que a inclusão das ciências sociais no currículo do ensino médio, no Brasil, respondia a necessidades derivadas de situações e processos inerentes ao modo

\footnotetext{
${ }^{5}$ A propósito, consultar Candido (1949); Costa Pinto (1949); Pierson (1949).

${ }^{6}$ Originalmente publicada nos Anais do I Congresso Brasileiro de Sociologia. São Paulo: Sociedade Brasileira de Sociologia, 1955, p. 89-106. Do mesmo período, ver também Ianni (1957).
} 
como se organizou e constituiu aqui a sociedade capitalista. Assim, às razões de ordem mais geral que inspiraram a pedagogia moderna e estimularam o estudo das ciências sociais nas escolas e universidades das sociedades burguesas ocidentais, sobrepunham-se no Brasil aquelas relacionadas com as peculiaridades de sua inserção nos movimentos do capitalismo monopolista mundial. Neste sentido, o ensino de Sociologia nas escolas de nível médio se justificaria como "fator consciente ou racional de progresso social", que permitiria reforçar os processos de socialização em um país socialmente, economicamente e culturalmente desigual.

Em sua reflexão sobre a viabilidade do ensino de Sociologia nas escolas de nível médio, Fernandes afirma sua possibilidade e necessidade, ainda que se mantenha a configuração do sistema educacional brasileiro, tal como ele se organizava nos anos 50 do século passado. Entretanto, diz ele, tendo em vista as finalidades formadoras da educação pelas ciências sociais, seria de suma importância que se alterassem a estrutura e as condições do sistema educacional brasileiro, no seu modo de funcionamento e na concepção pedagógica dominante. Aos sociólogos, restaria a tarefa e o desafio de intervir nas condições pedagógicas em que se daria 0 ensino da disciplina, que poderia preparar as novas gerações para o tratamento científico de problemas econômicos, políticos, administrativos e sociais em um país em formação.

\section{DESAFIOS CONTEMPORÂNEOS DA PRESENÇA DISCIPLINAR DA SOCIOLOGIA}

A tarefa e o desafio que Florestan Fernandes remeteu aos sociólogos nos anos 1950 permanecem vivos e inacabados nos dias de hoje. Com efeito, em um movimento inverso, verificou-se nas décadas posteriores um progressivo distanciamento dos sociólogos em relação à temática da educação e do ensino da disciplina em particular (SILVA et al., 2002). Segundo as autoras, foi entre 1930 e 1960 que o tema apareceu de modo mais freqüente em artigos publicados em revistas especializadas das ciências sociais ou da educação. Após este período, uma bibliografia esparsa, heterogênea e fragmentária tem tratado a questão do ensino de Sociologia no nível médio. Em sua interpretação destes dados, as autoras creditam o interesse dos cientistas sociais pelo tema ao processo de institucionalização da Sociologia no Brasil e à sua consolidação como disciplina científica, estreitamente articulados ao ingresso da disciplina no campo escolar.

Ao mesmo tempo, a própria problemática do processo educacional, analisado sob o ponto de vista de suas vinculações societárias, perde espaço na reflexão e na pesquisa sociológica. Segundo dados apresentados por Moraes (2003, p. 9), o tema "ensino de Sociologia" é inexistente nas teses e dissertações referidas à educação, defendidas nos 
programas de pós-graduação das ciências sociais na USP, entre 1945 e 1996.0 autor comenta que a Faculdade de Educação passou a contratar seus próprios professores de Sociologia da Educação, disciplina antes oferecida pelo Departamento de Sociologia da USP.

0 crescente distanciamento dos sociólogos em relação ao objeto "educação" pode ser explicado, como sugerem Ileizi Silva et al., pela estreita vinculação entre a institucionalização da Sociologia e sua aplicação no campo escolar. Masé possível supor que o afastamento da Sociologia da grade curricular obrigatória dos cursos de nível médio, nos mais de 40 anos que vão desde a Reforma Capanema (1942), durante o Estado Novo, até a primeira metade da década de 1980, quando a sociedade brasileira lutava contra a ditadura militar, tenha sido um outro fator importante deste distanciamento gradual.

As reformas educacionais implementadas pelos governos militares, após 1964, estimularam o controle privado da escola pública e estabeleceram a profissionalização compulsória e universal, induzindo a transformação do ensino médio em ensino profissionalizante, com a finalidade de formar força de trabalho técnica no período denominado de "milagre brasileiro". Ao mesmo tempo, permitiram uma maior dissociação entre licenciatura e bacharelado nas universidades, empobrecendo a formação de professores para o ensino básico. Quanto ao ensino de Sociologia, a disciplina, dentre outras humanísticas, científicas ou técnico-profissionalizantes, figurava como optativa nos currículos do curso colegial. A disciplina obrigatória Organização Social e Política Brasileira (OSPB) incorporava e difundia nas escolas as concepções conservadoras de sociedade, de nação e de modernidade defendidas pelos ideólogos do regime militar.

Como nos anos que se sucederam ao Estado Novo, os debates sobre o retorno da Sociologia à grade curricular obrigatória dos cursos de nível médio intensificam-se nos anos finais da ditadura militar, quando se reorganiza o movimento estudantil, ressurge a luta sindical e aparecem em cena novos movimentos sociais. ${ }^{7}$ Diversas entidades manifestam-se contra a desvalorização do ensino de Ciências Sociais nas escolas. Paulo Meksenas (1994, p. 18) cita a mobilização em São Paulo, liderada pela Associação dos Sociólogos (ASESP), que organizou o "dia estadual de luta pela volta da Sociologia ao $2^{\circ}$ grau”, em 27 de outubro de 1983, quando foi entregue à Secretaria de Educação do Estado um documento reivindicativo, defendendo a importância da Sociologia para a formação do jovem cidadão.

A Lei n ${ }^{\circ}$ 7.044/82 revogava a profissionalização compulsória do ensino de nível médio, no contexto de crise do chamado "milagre brasileiro", e a Resolução SE n 236/

${ }^{7}$ A respeito dos movimentos sociais em São Paulo, entre 1970 e 1980, ver Sader (1988). 
83, no Estado de São Paulo, permitia a inclusão da Sociologia na parte diversificada da grade curricular das escolas. Todavia, em seminários e fóruns realizados após a Resolução, constatava-se a escassez de material didático e a indefinição dos conteúdos programáticos relativos à Sociologia. Neste sentido, a mobilização dos setores vinculados à luta pela consolidação da disciplina no sistema escolar incorporou temáticas como a necessidade de cursos de atualização para os professores da disciplina e de concurso público para o cargo de professor de Sociologia, realizados pela Secretaria de Educação do Estado de São Paulo entre 1984 e 1986.

Em pesquisa realizada na região de Marília (SP) sobre o ensino de Sociologia nas escolas de nível médio, abrangendo o período de 1984 e 1993, Chammé e Mott (1996) constatam um aumento em aproximadamente $50 \%$ no número de escolas que incluem em seus currículos a disciplina. Entretanto, um conjunto de condições desfavoráveis a sua efetivação na grade curricularé apontado pelos autores, que se referem a problemas estruturais do sistema educacional brasileiro e a dificuldades advindas da situação específica da Sociologia no campo escolar. Segundo eles, a desvalorização da disciplinae do profissional especializado na ciência social, conseqüência da frágil presença disciplinar da Sociologia, é reforçada pelo processo educativo excludente e expulsivo, que afasta grande quantidade dos jovens brasileiros do ensino médio.

Uma retomada das discussões sobre o lugar da Sociologia no sistema escolar ocorre após a promulgação da última Lei de Diretrizes e Bases para a Educação, em 1996 (Lei n ${ }^{\circ}$ 9.394/96). Em seu artigo 36, parágrafo $1^{\circ}$, inciso III ela estabelece que o estudante, ao finalizar o ensino médio, demonstre "domínio de conhecimentos de filosofia e Sociologia necessários ao exercício da cidadania”. 0 inciso foi interpretado nas Diretrizes Curriculares Nacionais do Ensino Médio de 1998 (Parecer CNE/CEB n 15/98) como propondo um tratamento interdisciplinar e contextualizado para conhecimentos de filosofia e Sociologia, sem que isso necessariamente implicasse sua organização na forma de disciplina. Com a finalidade de superar tal situação de ambigüidade, um projeto de lei (PL n ${ }^{\circ}$ 09/00) aprovado na Câmara dos Deputados e no Senado alterava 0 artigo 36, parágrafo $1^{\circ}$, inciso III da Lei $n^{\circ} 9.394 / 96$ e afirmava a obrigatoriedade da disciplina de Sociologia, juntamente com a Filosofia, na grade curricular das escolas públicas. 0 projeto foi vetado em 2001, pelo então presidente da República, Fernando Henrique Cardoso.

Durante esse período, a definição a respeito da presença disciplinar da Sociologia nas escolas de nível médio ficou, na prática, a cargo dos Estados. Leis estaduais ou recomendações das secretarias estaduais de educação firmaram a adoção da disciplina como obrigatória em ao menos uma série/ano do Ensino Médio, em diversos Estados 
brasileiros. Em Santa Catarina, a decisão de obrigatoriedade da disciplina veio com a promulgação da lei estadual nº LC 173/98 (Art. $1^{\circ}$ ).

Em nível nacional, a reintrodução da disciplina ocorre com a homologação do Parecer 38/2006 do Conselho Nacional de Educação (CNE), de 11 de agosto de 2006, que torna obrigatório o ensino de Filosofia e Sociologia no Ensino Médio de todas as escolas públicas e privadas do país. De acordo com o parecer, os Estados terão um ano, a partir dessa data, para se adequarem à medida.

0 debate recente em torno da consolidação da Sociologia no campo escolar tem resultado no surgimento de novos materiais didáticos voltados para o ensino da disciplina nas escolas e a formação de professores do ensino básico. ${ }^{8}$ Ao mesmo tempo, foram defendidas dissertações de mestrado abordando o tema do ensino de Sociologia ou Ciências Sociais, ${ }^{9}$ enquanto em congressos nacionais de Sociologia os dilemas relativos ao ensino da disciplina e às experiências dos cursos de licenciatura em Ciências Sociais foram objeto de diversos trabalhos ali apresentados e discutidos. ${ }^{10}$ Também reunindo reflexões sobre o tema, destaca-se a publicação organizada por Carvalho (2004).

Em documento do Ministério da Educação, de 2006, intitulado "Orientações Curriculares para o Ensino Médio", o texto dedicado ao ensino de Sociologia apresenta uma crítica aos PCNs-Sociologia e às DCNEM, no que se refere ao papel da Sociologia nos currículos do Ensino Médio. Seus autores defendem a presença disciplinar da Sociologia e desenvolvem uma reflexão sobre as possibilidades educativas das ciências sociais e da Sociologia em particular, traçando um desenho analítico dos pressupostos metodológicos do ensino da disciplina nas escolas.

A licenciatura torna-se uma temática investigativa da maior importância nos dias de hoje, quando as novas formas de sociabilidade capitalista implicam dilemas e desafios no campo educativo, levando a um repensar de práticas e concepções pedagógicas. Ao mesmo tempo, reflexões e debates têm ocorrido no âmbito das universidades, buscando valorizar a licenciatura e o magistério e enfrentar a dissociação histórica entre licenciatura e bacharelado nos cursos de graduação.

\footnotetext{
${ }^{8}$ Exemplos de livros didáticos freqüentemente utilizados no ensino da Sociologia nas escolas são: Lakatos (1982); Meksenas (1985); Tomazi (2000); Vila Nova (1995); Costa (1997); Oliveira (2003).

9 Ver Correa (1993); Pacheco Filho (1994); Machado (1996); Giglio (1999); Meucci (2000); Guelfi (2001); Bispo (2002); Sarandy (2004); Reses (2004); Coan (2006).

${ }^{10}$ São exemplares os seguintes trabalhos apresentados no XII Congresso Nacional de Sociólogos: Barbosa e Mendonça, (2002); Meucci (2002); Silva, I. et al. (2002). No XI Congresso Brasileiro de Sociologia, realizado na Unicamp, Campinas, 2003, foi apresentado o trabalho de Mendonça (2003). No XII Congresso Brasileiro de Sociologia, realizado em maio de 2005, um grupo de trabalho concentrou a reflexão sobre o ensino de Sociologia: o GT 06 intitulado "Experiências de Ensino de Sociologia: Metodologia e Materiais Didáticos" (ver link http://www.sbsociologia.com.br/ congresso/). Apresentado em sessão especial, no mesmo congresso, o trabalho de Ileizi Silva (2005) discute desafios institucionais e epistemológicos para a consolidação da Sociologia no ensino médio.
} 
Na Universidade Federal de Santa Catarina, especialmente após a incorporação da Sociologia na grade curricular obrigatória do ensino médio no Estado, as discussões relativas à formação de professores, à realidade escolare às práticas de ensino de Sociologia nas escolas de nível médio resultaram em experiências organizativas e em atividades de pesquisa e extensão inovadoras, envolvendo professores da UFSC, do Colégio de Aplicação da universidade e das escolas estaduais de educação básica do Estado, além de alunos do curso de licenciatura em Ciências Sociais da UFSC.

Esse processo reflexivo e organizativo derivou na criação do Laboratório Interdisciplinar do Ensino de Filosofia e Sociologia (LEFIS), ${ }^{11}$ concretizado por convênio entre a UFSC e a Secretaria de Estado de Educação, que iniciou suas atividades em março de 2004. 0 LEFIS constitui-se em um trabalho interdisciplinar para desenvolvimento de atividades formativas e produção de material didático-pedagógico utilizado no ensino das duas disciplinas. Para os alunos do curso de Licenciatura em Ciências Sociais da UFSC, a participação em atividades formativas do LEFIS tem propiciado um processo reflexivo de aproximação e conhecimento da realidade escolar na qual irão atuar.

\section{REALIDADE ESCOLAR E EXPERIÊNCIAS Formativas EM SANTa Catarina}

Numa perspectiva de superação do distanciamento histórico das Ciências Sociais em face da problemática escolar, o trabalho realizado nas disciplinas de Metodologia do Ensino de Ciências Sociais e Prática do Ensino de Sociologia, do curso de Licenciatura em Ciências Sociais da UFSC, tem articulado atividades de ensino, pesquisa e extensão, buscando desvelar potencialidades educativas das ciências sociais e, ao mesmo tempo, permitir ao futuro professor compreender as determinações históricas e sociais que marcam o ensino de Sociologia nas escolas. Neste sentido, as experiências didáticas desenvolvidas nas duas disciplinas têm buscado articular estudos dos processos de ensino-aprendizagem em Ciências Sociais e dos seus fundamentos teóricos e metodológicos a uma análise da situação concreta do ensino de Sociologia nas escolas de nível médio, tomando a pesquisa da realidade escolar como ponto de partida desse desenho analítico (JINKINGS, 2006).

Um diagnóstico inicial dessa realidade tem sido obtido por meio de pesquisas desenvolvidas por licenciandos das Ciências Sociais em escolas de Florianópolis, que têm se voltado para aspectos como: as condições de trabalho e a formação do professor de Sociologia, a carga horária da disciplina, os conteúdos programáticos, os materiais e recursos didáticos utilizados, o perfil sócio-econômico dos alunos e seu comportamento em relação à disciplina, determinações históricas e filosóficas da prática docente na

\footnotetext{
${ }^{11}$ Para uma exposição mais detalhada do processo de criação e dos objetivos do LEFIS, ver Souza (2004).
} 
escola, suas condições espaciais e materiais. Este diagnóstico preliminar tem embasado atividades de extensão e as reflexões em sala de aula sobre o ensino das ciências sociais nas escolas.

Ao mesmo tempo, as investigações realizadas incorporam-se a um projeto de pesquisa vinculado ao Programa de Pós-Graduação em Educação da UFSC (JINKINGS; LIMA, 2005). Em seu desenvolvimento, o projeto adota perspectiva metodológica centrada em uma abordagem comparativa entre o período anterior à incorporação da Sociologia como disciplina obrigatória na grade curricular do Ensino Médio em Santa Catarina e o posterior, abrangendo o estudo um período de 10 anos, compreendido entre 1996 e 2006.

A investigação tem constatado uma permanência da situação de precariedade na qual se realiza o ensino de Sociologia, apesar da conquista da obrigatoriedade da disciplina nos currículos do ensino médio do Estado, há cerca de nove anos. De fato, lembrando Florestan Fernandes (1980b) quando, ao refletir sobre as potencialidades do ensino de Sociologia nas escolas de meados do século passado, afirmou que ele seria infrutífero sem uma mudança mais geral na estrutura do sistema educacional brasileiro, pode-se afirmar que a atual configuração do sistema não favorece que se desenvolvam as possíveis contribuições das ciências sociais para uma compreensão ampla da vida em sociedade. A proposta educacional para o Ensino Médio, em vigor, desconsidera singularidades e contradições da realidade social brasileira, mantendo problemas estruturais do sistema de ensino médio do país (KUENZER, 2000).

Ao lado de problemas que historicamente marcam a educação básica brasileira, como o quadro de marginalidade de grandes contingentes populacionais em relação ao processo educativo, somam-se as dificuldades particulares da situação da Sociologia no Ensino Médio, que decorrem de sua ainda frágil presença disciplinar. A ausência de tradição de trabalho com o ensino da Sociologia nas escolas, o desconhecimento sobre o sentido e a finalidade da disciplina na grade curricular e sua conseqüente desvalorização, tanto pelas direções das escolas e pelo seu coletivo de professores, como pelos alunos, obstaculizam a criação e a consolidação de espaços de reflexão sociológica que promovam mediações significativas entre os estudantes e o conhecimento científico da vida social.

Nas salas de aula das escolas, inteiramente articuladas a determinações mais gerais dos processos de ensino e aprendizagem, professores sobrecarregados de trabalho, muitas vezes sem a formação adequada para o ensino das ciências sociais e ministrando diferentes disciplinas, desenvolvem experiências pedagógicas descontextualizadas e fragmentadas, que não permitem uma compreensão totalizante do mundo social contemporâneo. Utilizando textos da grande imprensa, vários desses professores convertem as aulas de Sociologia em discussão de atualidades, tratando superficialmente 
acontecimentos em destaque na conjuntura nacional e/ou mundial, sem uma superação das explicações do senso comum. Outros desses professores apresentam em sala de aula conceitos tomados como estáticos, desconectados das teorias clássicas e dos princípios explicativos básicos das ciências sociais, não situados historicamente, tornando monótono e destituído de sentido o ensino de Sociologia. São professores que, em geral, não possuem planos de ensino e não elaboram um planejamento claro dos conteúdos e atividades a serem desenvolvidos ao longo do ano letivo, utilizando um ou outro livro didático de modo acrítico, desconsiderando as experiências e conhecimentos iniciais dos alunos e suas práticas sociais.

Tais experiências, que não devem ser generalizadas mas são significativas do contexto de precarização do sistema público de ensino, iluminam dimensões dos enormes desafios das ciências sociais, e da Sociologia em particular, relacionados aos processos educativos na sociedade capitalista do início do século XXI. Em face dessa realidade social, na qual se espera do comportamento humano que seja "flexível", isto é, adaptável à inovação incessante, como diz Richard Sennett (2000), o ensino e a pesquisa de Sociologia e das demais ciências sociais podem contribuir para uma apreensão crítica da vida social da atualidade e para o desvendamento de singularidades e contradições que marcam um mundo cindido por uma precarização social sem precedentes e pela mercadorização de todas as esferas da vida humana.

\section{REFERÊNCIAS}

ANTUNES, Ricardo. Os sentidos do trabalho: ensaio sobre a afirmação e a negação do trabalho. 3. ed. São Paulo: Boitempo, 2000.

AZEVEDO, Fernando. Princípios de Sociologia. 9. ed. São Paulo: Melhoramentos, 1964.

BARBOSA, Valéria; MENDONÇA, Suely. Licenciatura em Ciências Sociais: problemas e perspectivas. In: CONGRESSO NACIONAL DE SOCIÓLOGOS, 12., 2002, Curitiba. Anais... Curitiba, 2002.

BISPO, Mário. A Sociologia no ensino médio: o que pensam os professores da Rede Pública do Distrito Federal. Dissertação de Mestrado. Departamento de Sociologia, Universidade de Brasília, 2002.

BOTTOMORE, Tom; NISBET, Robert. (Org.). História da análise sociológica. Tradução de Waltensir Dutra. Rio de Janeiro: Zahar, 1980.

BRASIL. Ministério da Educação. Secretaria de Educação Média e Tecnológica. Parâmetros curriculares nacionais: ensino médio. Brasília, 1999. 
BRASIL. Ministério da Educação. Secretaria de Educação Básica. Orientações Curriculares Para o Ensino Médio: Ciências Humanas e suas tecnologias. Brasília, 2006. v. 3.

BRENNER, Robert. A Crise emergente do capitalismo mundial: do neoliberalismo à depressão? Revista do Instituto de Estudos Socialistas, São Paulo, n. 3, out. 1999.

CANDID0, Antonio. Sociologia; ensino e estudo. Sociologia: Revista Didática e Científica, São Paulo, v. 11, n. 3, p. 275-289, set. 1949.

. Literatura e sociedade. 5. ed. São Paulo: Ed. Nacional, 1976.

CARVALHO, Lejeune. (Org). Sociologia e ensino em debate: experiências e discussão da Sociologia no ensino médio. Ijuí: Ed. UNIJUİ, 2004.

CHACON, Wamireh. História das idéias sociológicas no Brasil. São Paulo: EDUSP/Grijalbo, 1977.

CHAMMÉ, Sebastião; MOTT, Yoshiko. A realidade do ensino de Sociologia no $2^{\circ}$ grau: inovações e continuidades. In: BICUDO, M.; BERNARDO, M. (Org.). Núcleos de ensino: um projeto de educação continuada. São Paulo: Unesp, 1996.

CHESNAIS, François. A mundialização do capital. trad. S. Foá. São Paulo: Xamã, 1996.

CIGLIO, Adriano. A Sociologia na Escola Secundária: uma questão das Ciências Sociais no Brasil- anos 40 e 50. Dissertação (Mestrado em Sociologia) - IUPERJ, Rio de Janeiro, 1999.

COAN, Marival. A Sociologia no Ensino Médio, o material didático e a categoria trabalho. Dissertação (Mestrado em Educação) - Universidade Federal de Santa Catarina, Florianópolis, 2006.

CORREA, Lesi. A importância da disciplina Sociologia no currículo de $2^{\circ}$. Grau. a questão da cidadania, problemas inerentes ao estudo da disciplina em 2 escolas oficiais de $2^{\circ}$. Grau de Londrina-PR. Dissertação (Mestrado em Educação) - PUC, São Paulo, 1993.

COSTA PINTO, Luís. Ensino da Sociologia nas escolas secundárias. Sociologia: Revista Didática e Científica, São Paulo, v. 11, n. 3, p. 290-308, set. 1949.

COSTA PINTO, Luís; CARNEIRO, Edison. As Ciências Sociais no Brasil. Rio de Janeiro: CAPES, 1955. (Série Estudos e Ensaios, n 6).

COSTA, Cristina. Sociologia: introdução à ciência da sociedade. 2. ed. São Paulo: Moderna, 1997.

FERNANDES, Florestan. Funções das ciências sociais no mundo moderno. In: PEREIRA, L.; FORACCHI, M. (Org.). Educação e sociedade. 9. ed. São Paulo: Ed. Nacional, 1978. p. 2228.

Desenvolvimento histórico-social da sociologia no Brasil. In: . A sociologia no Brasil: contribuição para o estudo de sua formação e desenvolvimento. 2. ed. Petrópolis: Vozes, 1980. p. 25-49.

. A 'crise' das ciências sociais em São Paulo. In: . A sociologia no Brasil: contribuição para 0 estudo de sua formação e desenvolvimento. 2. ed. Petrópolis: Vozes, 1980a. p. $85-86$. 
0 ensino de Sociologia na escola secundária brasileira. In: . A Sociologia no Brasil: contribuição para o estudo de sua formação e desenvolvimento. 2. ed. Petrópolis: Vozes, 1980b. p. 105-125.

A herança intelectual da Sociologia. In: FORACCHI, M.; MARTINS, J. S. (Org.). Sociologia e sociedade: leituras de introdução à Sociologia. 21. ed. Rio de Janeiro: LTC, 2000. p. 11-20.

GUELFI, Wanirley. A Sociologia como disciplina Escolar no Ensino Secundário Brasileiro: 1925-1942. Dissertação (Mestrado em Educação) - Universidade Federal do Paraná, Curitiba, 2001.

HOBSBAWM, Eric. Era dos extremos: o breve século XX (1914-1991). trad. M. Santarrita; revisão técnica M. C. Paoli. 2. ed., São Paulo: Companhia das Letras, 1997.

IANNI, Octavio. Sobre a inclusão da Sociologia no curso secundário. IV Congresso dos alunos da FFLCH da USP. Revista Atualidades Pedagógicas, ano 8, n. 40, p. 19-20, janabr., 1957.

. A Sociologia numa época de globalismo. In: FERREIRA, L. (Org.). A Sociologia no borizonte do século XXI. São Paulo: Boitempo, 1997. p. 13-25.

2001

Sociologia do futuro. Primeira Versão, n 100. Campinas: IFCH/Unicamp,

JINKINGS, Nise. As particularidades e os desafios do ensino de Sociologia nas escolas. In: M. F. DIAS et al. (Org.). Formação de professores: experiências e reflexões. Florianópolis: Letras Contemporâneas, 2006.

JINKINGS, Nise; LIMA, Silvia Auras de. A Sociologia no Ensino Médio: experiências docentes, formação e condições de trabalho do professor. Florianópolis: UFSC, 2005.

KUENZER, Acácia. 0 Ensino Médio agora é para a vida: entre o pretendido, o dito e o feito. Educação \& Sociedade, Campinas, ano 11, n. 70, abr., 2000.

LAKATOS, Eva. Sociologia geral. São Paulo: Atlas, 1982.

LIMONGI, F. Mentores e clientelas da Universidade de São Paulo. In: Miceli, S. (Org.). História das Ciências Sociais no Brasil. São Paulo: Vértice, 1989. v. 1.

MACHADO, Celso. 0 ensino de Sociologia na escola secundária brasileira: levantamento preliminar. Revista da Faculdade de Educação. São Paulo, v. 13, n. 1, p. 115-148, jan./ jun. 1987.

MACHADO, Olavo. 0 ensino de Ciências Sociais no nível médio. Dissertação (Mestrado) Faculdade de Educação, Universidade de São Paulo, São Paulo, 1996.

MEKSENAS, Paulo. Sociologia. 2. ed. rev. São Paulo: Cortez, 1994.

Aprendendo Sociologia: a paixão de conhecer a vida. São Paulo: Loyola, 1985.

MENDONÇA, Suely. Licenciatura em Ciências Sociais e Núcleo de Ensino/Unesp: trabalho diferenciado na formação de professores de Sociologia. In: CONGRESSO BRASILEIRO DE SOCIOLOGIA, 11., 2003, Campinas. Anais... Campinas: Unicamp, 2003. 
MEUCCI, Simone. Institucionalização da Sociologia no Brasil: os primeiros manuais e cursos. Dissertação (Mestrado em Sociologia) - Instituto de Filosofia e Ciências Humanas, Unicamp. Campinas, 2000.

. 0 significado do ensino de Sociologia no Brasil (1930-1950). In: CONGRESSO

NACIONAL DE SOCIÓLOGOS, 12., 2002, Curitiba. Anais... Curitiba, 2002.

MÉSzÁR0S, I. Beyond capital. London: Merlin Press, 1995.

MORAES, Amaury. Licenciatura em Ciências Sociais e ensino de Sociologia: entre o balanço e o relato. Tempo Social, Revista de Sociologia da USP, São Paulo, v. 15, n. 1, p. 5-20, maio 2003.

OLIVEIRA, Pérsio. Introdução à Sociologia. 24. ed. São Paulo: Ática, 2003.

PACHECO FILHO, Clovis. Dialogo de surdos: as dificuldades para a construção da Sociologia e de seu Ensino no Brasil. Dissertação (Mestrado em Educação) - FE-USP, São Paulo, 1994.

PIERSON, Donald. Difusão da ciência sociológica nas escolas. Revista Didática e Científica, São Paulo, v. 11, n. 3, p. 317-326, set. 1949.

RESES, Erlando. E com a Palavra: Os Alunos: estudo das representações sociais dos alunos da rede pública do Distrito Federal sobre a Sociologia no Ensino Médio. Dissertação (Mestrado em Sociologia) - Instituto de Ciências Sociais, Universidade de Brasília, Brasília, 2004.

SADER, Eder. Quando novos personagens entram em cena. São Paulo: Paz e Terra, 1988.

SARANDY, Flávio. A Sociologia volta à escola: um estudo dos manuais de Sociologia para o ensino médio no Brasil. Dissertação (Mestrado em Sociologia) - Universidade Federal do Rio de Janeiro, Rio de Janeiro, 2004.

SENNETT, Richard. A corrosão do caráter: conseqüências pessoais do trabalho no novo capitalismo. Trad. Marcos Santarrita. 4. ed. Rio de Janeiro: Record, 2000.

SILVA, Ileizi F. A Sociologia no ensino médio: os desafios institucionais e epistemológicos para a consolidação da disciplina. Sessão Especial: Ensino de Sociologia em questão. In: CONGRESSO BRASILEIRO DE SOCIOLOGIA, 12., 2005, Belo Horizonte. Anais... Belo Horizonte, 2005.

SILVA, Ileizi F. et al. 0 ensino de Ciências Sociais: mapeamento do debate em periódicos das ciências sociais e da educação de 1940-2001. Anais do XII CONGRESSO NACIONAL DE SOCIÓLOGOS, 12., 2002, Curitiba. Resumo... Curitiba, 2002.

SOUZA, Fernando P. Sociologia e Filosofia no Ensino Médio, em Santa Catarina. Mosaico Social: Revista do Curso de Graduação em Ciências Sociais, Florianópolis, ano 2, n. 2, dez., 2004.

TEIXEIRA, Francisco. Modernidade e crise: reestruturação capitalista ou fim do capitalismo? In: _. Novas determinações do mundo do trabalho. São Paulo: Cortez, 1996.

TOMAZI, Nelson (Org.). Iniciação à Sociologia. 2. ed. São Paulo: Atual, 2000.

VILA NOVA, S. Introdução à Sociologia. São Paulo: Atlas, 1995. 